\title{
Examining estradiols neuroprotective abilities and mechanisms of action in cerebrovascular accidents and neurodegenerative conditions
}

\author{
Sukanthatulsee Uthayabalan
}

\begin{abstract}
Estrogens are known for playing essential roles in the body. These hormones exert crucial protective actions when faced with neural damage. Numerous studies have provided a deep understanding of these unique actions that go far beyond the scope of reproduction and reproductive regulation. Through various mechanisms, delivery routes, dosage levels, and with the age and health status of the individuals receiving the treatment in mind, the hormone can be used in protecting against neural death. This review examines the discoveries that comprise the current body of knowledge regarding estrogen as a neuro-protector against cerebrovascular accidents (CVA, stroke) and neurodegenerative diseases. These findings have great implications for improving the quality of life in the aging population. They provide insight into the impact of hormones on the protection of neural tissues, and prompt discussion between members of the scientific community, ensuring that future clinical studies utilize methods that will maximize the quality of the obtained results.
\end{abstract}

Keywords: Neuroprotection; Estrogen; Estradiol; E2; Stroke; Neurodegeneration; Neural death

\section{Résumé}

Les estrogènes sont connus pour les rôles essentiels qu'ils jouent dans le corps. Ces hormones exercent des actions protectrices cruciales face aux dommages neuronaux. De nombreuses études ont fourni une profonde compréhension de ces actions uniques qui vont bien au-delà de la portée de la reproduction et la régulation de la reproduction. En tenant compte des divers mécanismes, itinéraires de livraison, niveaux de dosage, l'âge et l'état de santé des personnes recevant un traitement, l'hormone peut être utilisée comme protection contre la mort neuronale. Cet article examine les découvertes qui composent l'ensemble de connaissances actuelles en ce qui concerne les estrogènes en tant que neuro-protecteurs contre les accidents vasculaires cérébraux (AVC) et les maladies neurodégénératives. Ces résultats ont de grandes implications pour l'amélioration de la qualité de la vie pour la population vieillissante. Ils donnent un aperçu de l'impact des hormones sur la protection des tissus neuronaux et initient une discussion entre les membres de la communauté scientifique, veillant à ce que les futures études cliniques utilisent des méthodes qui maximisent la qualité des résultats obtenus.

Mots Clés: Neuroprotection; Estrogène; Estradiol; E2; ACV; Neurodégénérescence; Mort neuronale

\section{Introduction}

Estrogens are known as compounds that impact the regulation of the reproductive system; however, the roles of estrogens are not limited to this function (1). Estrogens possess potent protective factors in the context of many physiological systems, especially the nervous system. They protect against neural damage caused by cerebrovascular accidents (CVAs) and neurodegenerative dis-

Correspondence: tulsy21@yahoo.ca

Department of Biology, University of Ottawa, 30 Marie Curie, K1N 6N5,

Ottawa, Canada eases through specific mechanisms and pathways (2,3). Improving the understanding of the effects of estrogens will play a great role in modulating neurodegenerative conditions and in combatting the negative effects of CVAs.

Estrogen is a common steroidal sex hormone in women. Four natural estrogens are biosynthesized: estrone (E1), estradiol (E2), estriol (E3), and estetrol (E4) (4,5). E1 has a hydroxyl group at the C3 position, and a ketone group at the $\mathrm{C} 17$ position (5). It is an agonist of the estrogen receptors $\mathrm{ER} \alpha$ and $\operatorname{ER} \beta$ but is considered to be a 
weak estrogen (4). E3 consists of 3 hydroxyl groups and is produced in large amounts only during pregnancy (5). E4 has four hydroxyl groups, is produced mainly during pregnancy by the fetal liver and is closely related to E3 (5). Finally, E2, the strongest form of estrogen, is produced during the menstrual cycle and before pregnancy or menopause. It has two hydroxyl groups at the C3 and $17 \beta$ positions, as well as three double bonds on the phenolic A ring. This is the best estrogen to provide neuroprotective effects and can attenuate damage to neural tissue in animal models (5).

The discovery of three types of estrogen receptors (ER) which were traditionally thought to function as ligandactivated transcription factors (6) has caused a need to explore new mechanisms that may exist for estrogen action. Two classes of ERs exist: nuclear ERs (ER $\alpha$ and $\operatorname{ER} \beta$ ), which are members of the nuclear receptor family of intracellular receptors; and membrane ERs (mERs) (including GPER, GPR30 and ER-X), which are mostly G protein-coupled receptors (7). Estrogens produce their cellular actions, by binding these receptors. Gaining an understanding of the specific receptors and their corresponding actions allows for selective induction of the receptor pathway during treatment regimes. In this review, we examine the potential neuroprotective effects of E2 during the course of neurodegenerative diseases and CVAs. By examining these effects and the distinction between receptor/ non-receptor mediated mechanisms, it is possible to accumulate a greater body of knowledge regarding the clinical usage of E2 for treatment plans.

\section{Basic actions of estradiol}

E2 directly modulates cell death by acting on the neurochemical systems that are implicated in cognitive decline conditions, such as Alzheimer's Disease (AD), and in CVAs, such as ischemic stroke. Indirectly, it decreases cell aging by antagonizing the effects of oxidants and other neurotoxic compounds (8). E2 plays a key role in influencing various aspects of memory and cognition in healthy post-menopausal women (6). Most importantly, increased E2 levels delay the onset and progression of the form of cognitive decline that is typically associated with neurodegenerative diseases (7). Heightened levels of E2 play a large role in diminishing the harmful effects of acute-traumatic injuries associated with CVA while promoting neurogenesis ( 7 ).

\section{Evidence of Estrogen-Induced Neuroprotection}

Until recently, the majority of in vivo studies that investigated the mechanisms of injury in CVA and neurodegenerative diseases utilized males as models, assuming that any conclusions could be applied to females. Because females possess greater amounts of natural E2 compared to males, gender and E2 levels within the body play critical roles in protecting against neurodegeneration and CVA. Specifically, males have a minimum serum E2 concentration of $50 \mathrm{pmol} / \mathrm{L}(9)$. In females, serum E2 levels fluctuate depending on the menstrual cycle. The lowest level of serum E2 exists at the end of luteal phase (10). Here the minimum serum E2 concentration is $70 \mathrm{pmol} / \mathrm{L}(10)$. Even at the lowest natural levels, E2 appears in higher quantities in females than males. Studies indicate that due to these differences, females can better combat the harmful effects of the aforementioned conditions $(10,11)$. There are distinctions in the occurrence rate and outcome of neurodegeneration/CVA between the genders. Premenopausal women are at a reduced risk of experiencing an ischemic stroke compared to men (8). This disparity diminishes once these women are postmenopausal, indicating that E2 levels play a role in modulating age-related conditions of the brain. E2 has neuroprotective factors that diminish the effects of ischemic brain injury and neurodegeneration. Female rats that were given physiological doses of E2, sustained 50\% less infarctions than males and ovariectomized female rats, after ischemia induced by transient middle cerebral artery occlusion (MCAO) (6). Additionally, mice expressing the mutant human Alzheimer precursor protein $(\beta \mathrm{APP})$ showed reduced behavioural changes, delayed progression of neurodegeneration and a greater neural survival rate following the onset of a neurodegenerative disease when E2 was administered in early stages (6).

A large range of concentrations of E2 (105-1012 M), different neurotoxic stimuli (glucose deprivation, oxidative stress, physical injury) and various culturing methods (primary neuronal cells, mixed neuron/explant cultures) have been used to test treatments (5). The dose administered is crucial as there is a high sensitivity to natural E2 levels (12). One study demonstrated neuroprotection (in the form of reducing ischemic injury and the progression of neurodegeneration) with acute pharmacological $(1 \mathrm{mg} / \mathrm{kg} 1)$ doses of $\mathrm{E} 2$ in male rats, but, identical doses in females failed to have any effect. Similarly, lower physiological doses were effective in reducing both ischemia and cognitive decline in ovariectomized female rodents, but similar doses in un-ovariectomized females failed (12). Here, naturally occurring E2 creates a tolerance. E2 administered to models with naturally high levels of the hormone must be increased for effects to be seen. However, administering the same dose of E2 to males or ovariectomized females is effective as natural E2 levels in these models are already low and thus, a tolerance is not present (12). This implies that precise doses based on sex, age, and natural E2 levels in the body are needed to see results. Moreover, these treatments were administered before and after CVA and the onset of neurodegeneration (6). Results showed that to see results, E2 should be administered in its lowest physiological concentration before a CVA. In the case of neurodegeneration, 
administration of the lowest physiological dosage in the earliest stages of onset is critical (6).

\section{Mechanisms of Estrogen Action}

E2 protects the brain in adults by altering the ability of neurons to survive post-trauma. E2 acts on other cell types, such as vascular endothelial cells and microglia, through either estrogen receptor (ER)-dependent or independent mechanisms. The mechanism used depends upon the area of the brain involved in neuroprotection while the pathway of E2 action is influenced by the dose administered (13).

\section{Non-Genomic}

Some E2 receptors associate with the cell membrane and are rapidly activated by exposing the cell to E2. Pharmacological levels of E2 bypass cellular (cytosolic) ERs and act through membrane ERs. These receptors associate with cell membranes by attachment to caveolin-1, a scaffolding protein in plasma membranes, and form complexes with $\mathrm{G}$ proteins, striatin, receptor tyrosine kinases, and non-receptor tyrosine kinases (Src) (14). Through striatin, the membrane bound ER can lead to increased levels of $\mathrm{Ca}^{2+}$ and nitric oxide (NO) (14), eliciting antioxidant effects. Through the receptor tyrosine kinases, signals are sent to the nucleus through the mitogen activated protein kinase (MAPK/ERK) pathway and phosphoinositide 3-kinase (PI3K/AKT) pathway, producing changes in cell function (10).

\section{Genomic}

In the absence of hormone attachment, E2 receptors $(\mathrm{ER} \alpha$ and $\mathrm{ER} \beta)$ are located in the cytosol. E2 binding to its receptor leads to downstream events including migration of the receptor from the cytosol into the nucleus, receptor dimerization and binding of the receptor to estrogen response elements (ERE) on DNA. The DNA/receptor complex then recruits proteins (DNA Polymerases) that are responsible for the transcription of downstream DNA into mRNA (14). Finally, a change in cell function results (14). Here, physiological levels of E2 protect the brain through mechanisms dependant upon cytosolic ERs.

\section{Receptor-Mediated Neuroprotection Membrane (Classical) Estrogen Receptors (ER)}

E2 classically exerts its effects via a nuclear membrane ER mechanism. E2 enters the cell by passive diffusion and binds to the nuclear ER. Following a series of activation steps, the E2-ER complex associates with the estrogen response element (ERE) and functions as an enhancer for ERE-containing genes $(14,15)$. E2 induction of ERE-containing genes contributes to the neuroprotective effects of the hormone. To evaluate the role of membrane ERs as mediators of E2 neuroprotection in a model of global ischemia, ICI 182 780, a competitive membrane ER antagonist antagonist of E2, was delivered intracerebroventricularly (ICV) during the early post-ischemic period (at 0 and 12 hours after reperfusion) (13). Results revealed that the antagonist, ICI 182,780, reduced E2-elicited neuroprotection (13). When E2 was administered alone, the hormone promoted neuronal survival (6). When the membrane ER was antagonized, E2 could not bind to it at the nuclear membrane of neuronal cells by attaching to membrane proteins. Thus, signals were not sent to the nucleus through the MAPK/ERK and $\mathrm{Pl3K} / \mathrm{AKT}$ pathways, preventing changes in cell function and reducing neuroprotection in damaged cells.

Additionally, the membrane ER, GPR30's role in mediating estrogen signaling and neuroprotection in the hippocampus following global cerebral ischemia GCI was examined. An E2 conjugate, E2-BSA, which exerted rapid regulation of kinase activation and neuroprotection in the hippocampal CA1 region of ovariectomized adult rats was used (16). GPR30 was knocked out by bilateral administration of antisense (AS) oligodeoxynucleotides every 24 hours for 4 days. On the fourth day, a GCI was performed. E2-BSA (10 $\mu \mathrm{M}$ in $5 \mu \mathrm{l} 0.9 \%$ saline) was administered bilaterally via ICV injection 60 minutes before induction of GCI (16). E2-BSA treatment resulted in neuroprotection, indicated by a significant increase in surviving neurons in the CA1 region in the GPR30active control group. GPR30 knockout greatly reduced the neuroprotective effect of E2-BSA in the CA1 region of the experimental group, after GCI. Finally, administration of the GPR30 agonist, G1, with E2-BSA exerted a strong neuroprotective effect against GCI-induced neuronal cell death in the CA1 region in both groups (16). The study demonstrates the importance of membrane receptors that act in membrane ER-based neuroprotection. Knocking out GPR30 with AS prevents E2-BSA from binding to the cell membrane entirely, increasing GCI-induced neuronal cell loss.

\section{Estrogen Receptor (ER) $\alpha$ and Estrogen Receptor (ER) $\beta$}

In the central nervous system (CNS), although ERs (alpha and beta) co-express in some regions, others show selective expression (ER $\alpha$ in the ventromedial hypothalamic nucleus and subfornical organ, $\operatorname{ER} \beta$ in the cerebral cortex/hippocampus), indicating that expression of ER in the brain is subtype-specific (6). These subtypes undergo ligand activation. This leads to the formation of a receptor dimer with high affinity for specific DNA sequences called estrogen response elements, (EREs) within promoters of target genes (17). One investigation used homozygous $\operatorname{ER} \alpha$ and $\operatorname{ER} \beta$-knockout mice to determine the efficacy of E2 and concluded that ER $\alpha$ played a key role in protecting against neuronal injury in 
animals undergoing MCAO (18). The results showed that deletion of $\mathrm{ER} \alpha$ in mice eliminates the neuroprotective effect of E2 in all regions of the brain, while the capability of $\mathrm{E} 2$ was preserved for neuroprotection against this brain injury in the absence of $\operatorname{ER} \beta$ (18). The results denote that $\mathrm{ER} \alpha$ is a critical mechanistic link in mediating the protective effects of $\mathrm{E} 2$ in brain injury.

Additionally, physiological levels of E2 cannot delay the progression of cognitive decline or protect against ischemic stroke in ER $\alpha$ knock-out mice (19). This finding stresses ER $\alpha$ 's critical role in mediating E2's effects. Gollapudi and Oblinger's studies show that PC12 cells (derived from rat adrenal medulla) transfected with the full-length rat $\mathrm{ER} \alpha$ respond to the protective effects of E2 while cells transfected with vector DNA alone do not, further cementing the theory that $\mathrm{ER} \alpha$ is a crucial mechanism that mediates the neuroprotective effects of physiological levels of E2 (20). To evaluate the role of $\mathrm{ER} \alpha$ vs $\mathrm{ER} \beta$, subtype-selective agonists were administered daily for 2 weeks before and 7 days after ischemia (13). Both propyl pyrazole triol (PPT, ER $\alpha$-agonist) and WAY 200070-3 (ER $\beta$-agonist) promoted the survival of nearly all CA1 pyramidal neurons in approximately $50 \%$ of the animals (13), suggesting that E2 acts through both $\mathrm{ER} \alpha$ and $\mathrm{ER} \beta$ to protect CA1 neurons, though $\mathrm{ER} \alpha$ may be a more commonly used receptor.

Another study showed that within 24 hours of MCAO, $\mathrm{ER} \alpha$ is dramatically up-regulated and $\mathrm{E} 2$ pretreatment prevents injury-induced down-regulation of $\operatorname{ER} \beta$ in the cerebral cortex (21). These findings suggest that any form of brain injury or degeneration causes increased responsiveness of the injured region to E2. This induces actions that are specific to each subtype of the receptor. Normally, high levels of $\mathrm{ER} \alpha$ are only expressed in the cerebral cortex (CC) during neonatal development (22). Following this stage, the expression of $\mathrm{ER} \alpha$ in the $\mathrm{CC}$ is minimal. Post-injury, the substantial increase in $\operatorname{ER} \alpha$ caused by up-regulation causes an increase in estrogen in the area of injury, evoking a hormonal state that is similar to a neonatal brain (22). Following injury, this process then promotes neurogenesis and re-differentiation of the cortex, similar to the process in a neonatal (19).

Due to the presence of $\operatorname{ER} \beta$ and injury-induced up regulation of $\mathrm{ER} \alpha$, the expression of the anti-apoptotic gene, bcl-2, is increased in the ischemic penumbra (area impacted by ischemic event), the $\mathrm{CC}$, and basal ganglia (area impacted by neurodegenerative diseases). E2 affects the expression of genes that are involved in regulating apoptosis and in activating ERs, leading to enhanced neuronal viability (11,22). Estrogen's ability to exert any receptor-mediated neuroprotection correlates with differential expression of $\operatorname{ER} \alpha$ and $\operatorname{ER} \beta$ mRNA in the CC.

\section{Non-Receptor-Mediated Neuroprotection}

While many E2 analogues require membrane or cellular receptors, unique derivatives function without receptormediation. These analogues rapidly decrease N-methylD-aspartate (NMDA)-induced currents, reducing excitatory cell death caused by neurodegeneration or CVA (22). To examine non-receptor mechanisms of neuroprotection in CVAs, cytotoxicity was induced in HT-22 (mouse hippocampal) cells by $10 \mathrm{mmol} / \mathrm{L}$ glutamate. A novel non-receptor estrogen analogue (ZYC3) was added immediately before the exposure to glutamate and then an ischemia/reperfusion injury was induced by temporary MCAO. ZYC3 did not bind to $\mathrm{mER}, \mathrm{ER} \alpha$ or $\mathrm{ER} \beta$ (23). The infarct volume was significantly reduced to $122.4 \pm 17.6$ in ZYC3 groups, compared with $252.6 \pm 15.6$ $\mathrm{mm}$ in the ovariectomized group (23). This occurs because ZYC3 increases cerebral blood flow in both sides of the brain within 30 minutes after reperfusion during MCAO, preventing cell death. In neurodegeneration, E2 influences members of the nitric oxide synthase family to induce vasodilatory actions on cerebral blood vessels, improving blood flow to compromised brain regions. These unique analogues of E2 are potent antioxidants and inhibit lipid peroxidation through the C3 hydroxyl group located and the phenolic A-ring of E2 and through the nitric oxide synthase family $(10,24)$. The reduction of perioxidation permits the reduction of overall cell death caused by neurodegeneration. This implies that nonreceptor mechanisms of E2 neuroprotection are beneficial for neuroprotection against oxidative stress injuries as well as CVA related damage.

\section{Future Directions and Questions to Consider}

With newfound knowledge regarding estrogen, it may be possible to utilize natural/synthetic compounds to prevent neural death and to delay the onset of neurodegenerative diseases. Studies show that serum estrogen levels are inversely correlated with ischemic stroke damage in intact animals. Treatment of intact female mice with an anti-estrogen receptor compound, ICI182,780, greatly enhances stroke infarct size (10). This emphasizes the possibilities for treatment and prevention with E2. In future therapies for individuals coping with $\mathrm{AD}$ or ischemic stroke, E2 could be utilized to attenuate neural necrosis. These therapies could be utilized to alleviate the troublesome symptoms in post-menopausal women while reducing risks of cerebro-vascular disease. Questions that arise are plentiful because of the novel actions of E2. It is important to consider the availability of E2 therapies, whether or not neuroprotective actions of E2 are reversible, the window of opportunity for administration of treatment where E2 is most effective, whether or not the positive effects will endure if treatment is discontinued and the duration for which this would occur. These 
potential limitations must be overcome with experimentation prior to distribution of treatments, in order to amplify positive results.

\section{Conclusion}

E2 is a complex and powerful hormone that produces favourable results in treating CNS injuries, as a protective agent. E2 attenuates the extent of injury incurred by increasing the resilience of the brain via receptormediated/receptor-independent mechanisms in both oxidative stress, and CVA-induced injuries. While many studies have come up with breakthrough results, limitations still exist. Further research must be conducted in order to fully understand the molecular mechanisms of E2 action. Challenges for the future include i) understanding how E2 therapy in men will impact feminization, and ii) combatting negative effects of high levels of E2 such as thrombosis, which can lead to severe cardiovascular problems. Combining various types of biosynthetic estrogens and therapy methods (e.g. oral, transdermal) may aid in administering controlled doses of the hormone, reducing side effects. This form of therapy can even provide an opportunity to use two different therapeutic agents at very low doses for additive or synergistic effects (e.g. E2 with an agonist) to improve the overall therapeutic outcomes. Despite limitations, E2 maintains the hope for successful neuroprotection in different CNS injuries. Current findings may lead to utilizing estrogens to target specific tissues for therapy, further eliminating unwanted side effects. In the future, acquiring a better understanding of E2 and its workings will facilitate the development of innovative therapies, significantly impacting the aging population by improving coping ability and quality of life.

\section{Competing interests}

The author declares that she has no competing interests.

References

1. S. Suzuki, C. M. Brown, P. M. Wise, Front Neuroendocrinol 30, 201 (2009).

2. P. S. Green, J. W. Simpkins, Int. J. Dev. Neurosci. 18, 347 (2000).

3. M. Fiocchetti, P. Ascenzi, M. Marino, Front Physiol 3, 73 (2012).

4. L. M. Garcia-Segura, I. Azcoitia, L. L. DonCarlos, Progress in neurobiology 63, 29 (2001)

5. N. Raghava, B. C. Das, S. K. Ray, Neurosci Neuroecon 6, 15 (2017)

6. L. Zhao, T. W. Wu, R. D. Brinton, Brain Res. 1010, 22 (2004).

7. S. Pozzi, V. Benedusi, A. Maggi, E. Vegeto, Ann. N. Y. Acad. Sci. 1089, 302 (2006).

8. R. Norbury, et al., Exp. Gerontol. 38, 109 (2003).

9. D. B. Dubal, P. M. Wise, Endocrinology 142, 43 (2001).

10. D. W. Brann, K. Dhandapani, C. Wakade, V. B. Mahesh, M. M. Khan, Steroids 72, 381 (2007)

11. V. I. Alexaki, et al., FASEB J. 18, 1594 (2004).

12. L. D. McCullough, P. D. Hurn, Trends Endocrinol. Metab. 14, 228 (2003).

13. A. M. Etgen, T. Jover-Mengual, R. S. Zukin, Front Neuroendocrinol 32, 336 (2011).

14. P. M. Wise, S. Suzuki, C. M. Brown, Dialogues Clin Neurosci 11 297 (2009).
15. C. Behl, Nature reviews. Neuroscience 3, 433 (2002).

16. H. Tang, et al., Mol. Cell. Endocrinol. 389, 92 (2014).

17. I. Paterni, C. Granchi, J. A. Katzenellenbogen, F. Minutolo, Steroids $\mathbf{9 0}$, 13 (2014).

18. R. D. Spence, et al., Proc. Natl. Acad. Sci. U.S.A. 108, 8867 (2011).

19. D. G. Stein, Trends Neurosci. 24, 386 (2001).

20. L. Gollapudi, M. M. Oblinger, J. Neurosci. Res. 56, 471 (1999).

21. J. W. Simpkins, M. Singh, C. Brock, A. M. Etgen, Neuroendocrinology 96, 119 (2012).

22. A. L. Mize, R. A. Shapiro, D. M. Dorsa, Endocrinology 144, 306 (2003).

23. R. Liu, et al., Stroke 33, 2485 (2002).

24. Q. Wang, R. Santizo, V. L. Baughman, D. A. Pelligrino, C. ladecola, Stroke 30, 630 (1999). 